\title{
Treatment of scleroderma heart by D-penicillamine
}

\author{
Martin Muers ${ }^{1}$ and Wilfred Stokes \\ From the Department of Medicine, Stoke Mandeville Hospital, Aylesbury, Bucks
}

$A$ case of severe diffuse systemic sclerosis with cardiomegaly and cardiac failure is described. Treatment with D-penicillamine caused a pronounced decrease in heart size, together with clinical improvement. The use of penicillamine in scleroderma heart has not previously been reported.

The use of $\mathrm{D}$-penicillamine in the treatment of scleroderma (diffuse systemic sclerosis) was first reported by Fulghum and Katz (1968). Subsequently several articles have appeared reporting encouraging results, e.g. Bluestone et al. (1970), Tio, Van Wijk, and de Haan (1973), and Thomson and Milne (1974). In none of these papers, however, has the effect of D-penicillamine upon the scleroderma heart been reported. In the case described below cardiomegaly and mild congestive cardiac failure caused by scleroderma responded well to D-penicillamine.

\section{Case report}

A 24-year-old West Indian nurse presented with Raynaud's disease in 1968. By 1970 this had progressed to severe fingertip ulceration, but there appeared to be no other skin involvement, the heart was not enlarged, and a barium swallow and chest $x$-ray film were normal (Fig. 1A). In 1971, sclerodactyly became pronounced and, in addition, there was skin tightening of the anterior chest wall and nasal bridge. Treatment of the Raynaud's disease was begun with griseofulvin. Dysphagia, limb muscle weakness, and obvious stiffness of the knees and elbow joints developed early in 1972, when a second barium meal showed the typical oseophagus of scleroderma, and cardiomegaly was present on $x$-ray examination for the first time (Fig. 1B). A skeletal muscle biopsy showed a fibrosis compatible with a diagnosis of diffuse systemic sclerosis.

Although treatment with prednisolone $(20 \mathrm{mg}$ daily) was begun (June, 1972) a decrease in exercise tolerance occurred three months later, in the absence of arrhythmias or systemic hypertension. Cardiomegaly was more pronounced on $x$-ray film, but heart sounds were normal

1Present address: Chest Department, Churchill Hospital, Headington, Oxford. and no failure was present. The electrocardiogram now showed left axis deviation, and widespread $T$ wave inversion (Fig. 2A). Lung function tests showed a reduced transfer factor of $13.1 \mathrm{ml} \mathrm{CO} / \mathrm{min}$ per $\mathrm{mmHg}$ (expected normal 29.3) and a reduced total lung capacity of 3.651 (expected normal 5.83 1). Lymphocyte transformaticn studies in the presence of a muscle antigen showed a high positive value of 445 counts/min, compatible with an active myositis.

By March 1973 the patient's exercise tolerance had worsened further, despite treatment with prednisolone (10 $\mathrm{mg}$ daily), and the introduction of digoxin $(0.25 \mathrm{mg}$ o.d.) and diuretic therapy. On examination the patient presented as a thin woman, with severe sclerodactyly gross restriction of facial mobility, and sclerodermatous plaques on the anterior chest wall, and on the thighs. There was persistent joint pain and limitation of movement, particularly of the hips and knees. Tachycardia was absent at rest and there was no pulsus paradoxus. There was pronounced cardiomegaly and a soft mitral third sound. Blood pressure was $130 / 70 \mathrm{~mm} \mathrm{Hg}$ $(17 \cdot 3 / 9 \cdot 1 \mathrm{kPa})$.

Six months later the symptoms remained and the clinical, $x$-ray film, and electrocardiographic appearances had deteriorated (Fig. 1C and Fig. 2B). The mitral third sound was louder and in addition a soft pansystolic murmur of mitral regurgitation was audible. Antinuclear factor was positive (1/1024), lupus erythematosus cells were absent, and the serum complement $\mathrm{C}_{3}$ level was 64 units $/ \mathrm{ml}$.

Because the patient's clinical condition was worsening despite conventional therapy, D-penicillamine treatment was begun in September 1973, with a dose of $150 \mathrm{mg}$ daily. This was increased gradually over the succeeding weeks to a maintenance dose of $150 \mathrm{mg}$ t.d.s. Concurrently the dose of prednisolone was reduced from 10 to $3 \mathrm{mg}$ daily, but the other drugs were continued unchanged.

A slow and gradual improvement in the patient's condition ensued. After six months' treatment with 

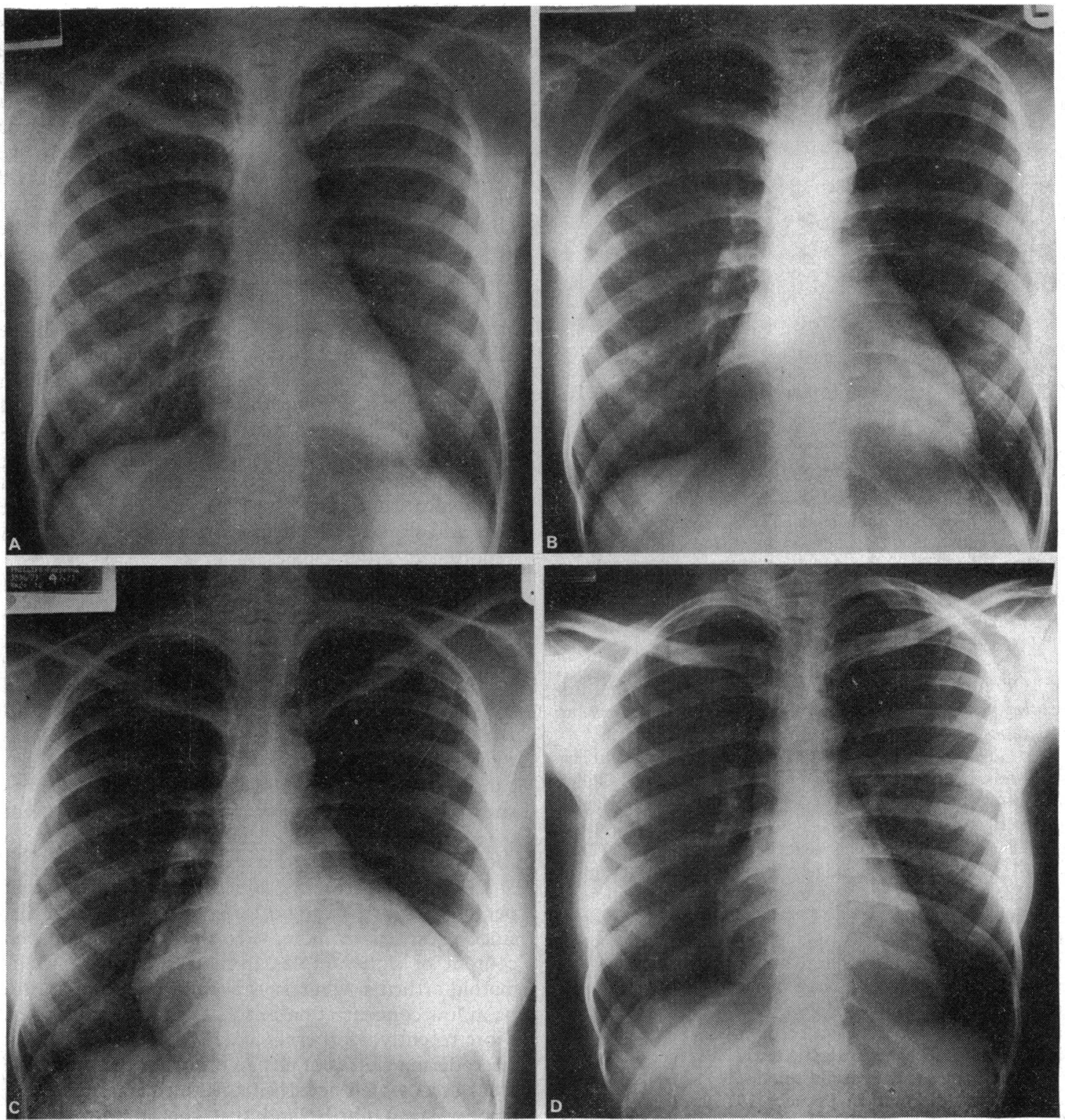

FIG. 1 Chest X-ray films from patient with scleroderma heart. $(A)$ before cardiac involvement (1970); (B) three months before treatment with digoxin and steroids (1972). Cardiac enlargement persisted for 15 months (C) (1973), and D-penicillamine treatment was started 2 months later. (D) Reduction in cardiomegaly after 14 months' therapy (1974).

D-penicillamine, during which there had been no haematological or urinary abnormalities, there was a subjective increase in well-being, and an improvement in exercise tolerance to grade IIb. After a further nine months the patient was reviewed; there was an increase in facial mobility, and in joint laxity. There were now no firm plaques and no new digital ulceration. The heart was smaller (Fig. 1D) and the mitral murmur was absent and the third sound softer. There was no evidence of congestive failure and the blood pressure was unchanged. The electrocardiogram had reverted to its appearance of 1972, with reduced $T$ wave inversion (Fig. 2C). Lung function tests at this time (November 1974) showed a slight increase in transfer factor from 13.3 to 14.3 


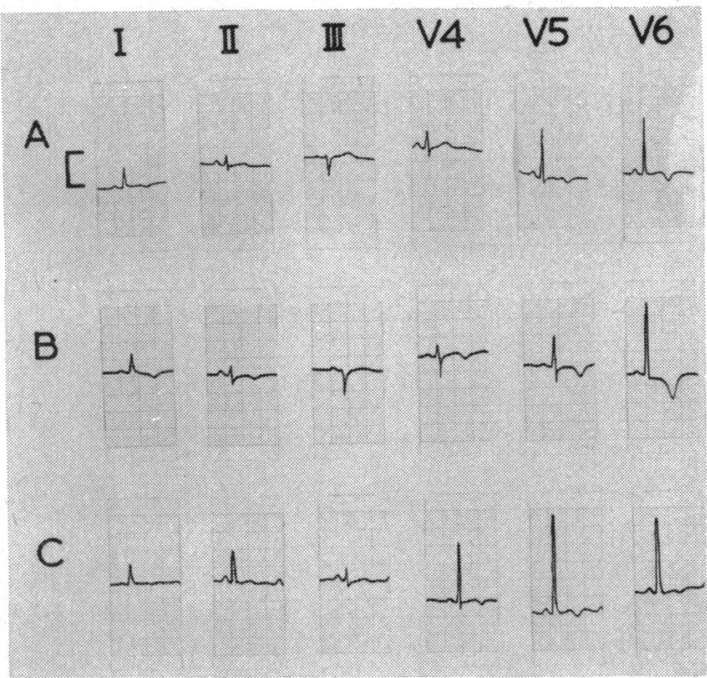

FI G. 2 Electrocardiograms from patient with scleroderma heart. (A) After 6 months', and (B) after 14 months' treatment with steroids and digoxin but before the D-penicillamine; (C) after 15 months' treatment with D-penicillamine.

$\mathrm{ml} \mathrm{CO} / \mathrm{mm} \mathrm{H}_{2} \mathrm{O}$ per min, and an increase in total lung capacity from 3.651 to 4.671 . Barium swallow appearances had reverted to normal.

At the invitation of Dr. S. Oram the patient was transfered to the Cardiac Department at King's College Hospital, London, where right heart catheterization showed right ventricular pressure of $32 / 8 \mathrm{~mm} \mathrm{Hg}$ $(4 \cdot 3 / 1.0 \mathrm{kPa})$, pulmonary artery pressure of $32 / 12 \mathrm{~mm}$ $\mathrm{Hg}(4.3 / 1.6 \mathrm{kPa})$, and wedge pressure (mean) $10 \mathrm{~mm} \mathrm{Hg}$ $(1.3 \mathrm{kPa})$. Two right ventricular endomyocardial biopsies were obtained by Dr. P. J. Richardson. Histological examination by Dr. E. G. J. Olsen showed normal muscle and vascular architecture, with no fibrosis. A repeat skeletal muscle biopsy was obtained from the left deltoid, and section here likewise showed no evidence of active muscle degeneration or myositis, but a slight increase in the fibrous interstitium.

Treatment with prednisolone ( $3 \mathrm{mg}$ daily) and digoxin was stopped in January 1975 and in the intervening period the patient has been well. Her only symptoms recently have been of breathlessness at grade IIa exertion and occasional palpitations. The cardiac outline remains smaller on $x$-ray film. The only treatment besides D-penicillamine $125 \mathrm{mg}$ b.d. is now bendrofluazide $5 \mathrm{mg}$ daily with potassium supplementation, griseofulvin, and pyridoxine, the metabolism of which is disturbed by penicillamine (Gibbs and Walshe, 1966). The patient has returned to work.

\section{Discussion}

Involvement of the heart in systemic sclerosis is rare compared with other viscera such as oesophagus or lungs, and an analysis of published data (Oram and Stokes, 1961) showed that it had been found on average in less than 15 per cent of cases. The heart is more commonly affected secondary to scleroderma of the lungs (Sackner et al., 1964), but can be directly involved alone (D'Angelo et al., 1969), and this may occasionally be the presenting feature of the disease. Necropsy studies have shown that the myocardium is primarily involved and that pericardial and endocardial damage is rarer. Cardiac symptoms usually occur late in the disease, and life expectancy is then short, averaging 30 months in the 21 patients personally treated by Oram and Stokes (1961). Electrocardiographic abnormalities, which may be various, are most often the first evidence of scleroderma affecting the heart, and the most common abnormality is an appearance suggesting myocardial ischaemia or infarction, as in this case. When the myocardium is involved, cardiac dilatation is the rule and grossly enlarged $x$-ray outlines have been reported in other papers.

Penicillamine ( $\beta, \beta$ dimethyl cysteine) was first introduced as a therapeutic agent by Walshe (1956, 1960) for the treatment of hepatolenticular degeneration (Wilson's disease). Its possible usefulness in the connective tissue disorders was suggested by Jaffe (1963) who showed a fall in the titre of rheumatoid factor in patients with severe rheumatoid arthritis when penicillamine was given. A careful double-blind trial (Andrews et al., 1973) has shown its superiority over placebo in the treatment of severe rheumatoid arthritis, and it is now in routine use for this disease (Golding, 1973).

In 1966, Harris and Sjoerdsma suggested that penicillamine was a logical therapy for scleroderma, since it caused an increase in the 'soluble' collagen content of skin samples from patients with rheumatoid arthritis, whereas this collagen was found to be in low concentration in sclerodermatous plaques. More recently, Herbert et al. (1974) have shown that scleroderma skin contains an excess of the reducible cross links which occur in mature collagen between tropocollagen fibrils, and that this abnormal preponderance is reduced after treatment with penicillamine. The implication is that in active, but not in well-established lesions, penicillamine may produce an improvement as it can inhibit the formation of these links as collagen is laid down.

Clinical experience with penicillamine in systemic sclerosis has been varied and sporadic and to date no comparative trials have been published. Bluestone et al. (1970) reported that 6 of 9 treated patients with systemic disease showed an objective improvement in skin elasticity, and Moynahan (1973) has shown a consistent clinical improvement in child- 
hood morphoea treated with this drug. A 12-yearold girl with multisystem disease treated with penicillamine for two years showed, similarly, improvement in cutaneous, oesophageal, and Raynaud symptoms, but had no change in lung function, erythrocyte sedimentation rate, or antinuclear factor titre (Thomson and Milne, 1974),

The association of a cardiac lesion with scleroderma does not necessarily establish the presence of scleroderma in the heart. However, the undoubted clinical syndrome of diffuse disease in our patient, coupled with the absence of any other explanation for the pronounced cardiomegaly, electrocardiographic abnormalities, and cardiac failure, seem to justify the diagnosis. A negative right ventricular endomyocardial biopsy after 15 months' treatment does not necessarily deny it, since the sclerodermatous process is patchily distributed within the myocardium, and the endocardium frequently escapes (D'Angelo et al., 1969). At the start of the penicillamine therapy, with multisystem disease affecting both heart and lungs, this patient's condi tion would not have been expected to improve. A series of $x$-ray films in the absence of any clinical evidence of pericardial effusion indicated that the cardiomegaly had persistently worsened for 10 months, despite steroid therapy. After penicillamine treatment was begun, however, the heart size steadily decreased and this change was accompanied pari passu by an improvement in the electrocardiogram, an increase in skin and joint suppleness, and loss of muscle stiffness. This decrease in cardiomegaly cannot be ascribed to the continued low dose of steroids, since this is not known to cause cardiac resolution in much larger doses, and the small dose was continued in this patient primarily as supportive treatment for the joint pain, as was the griseofulvin for the Raynaud's disease. We cannot exclude the possibility from a single case history that a spontaneous remission in the disease has taken place. However, a spontaneous remission in advanced disease so rapid and complete would be unexpected, and we conclude that the use of penicillamine contributed to the improvement in this patient's scleroderma heart.

We are indebted to Dr. Margaret Walshe for advice on the dermatological aspects of this case to Dr. Samuel Oram, Dr. P. J. Richardson, and Dr. E. G. J. Olsen for arranging the endomyocardial biopsy, and Dr. Elizabeth Hills for doing the lung function tests.

\section{References}

Andrews, F. M., Golding, D. N., Freeman, A. M., Golding, J. R., Day, A. T., Hill, A. G. S., Camp, A. V., LewisFaning, E., and Lyle, W. H. (1973). Controlled trial of D(-)penicillamine in severe rheumatoid arthritis. Lancet 1 , 275.

Bluestone, R., Grahame, A., Holloway, V., and Holt, P. J. L. (1970). Treatment of systemic sclerosis with D-penicillamine: a new method of observing the effects of treatment. Annals of the Rheumatic Diseases, 29, 153.

D'Angelo, W. A., Fries, J. F., Masi, A. T., and Shulman, L. E. (1969). Pathologic observations in systemic sclerosis (scleroderma). American fournal of Medicine, 46, 428.

Fulghum, D. D., and Katz, R. (1968). Penicillamine for scleroderma. Archives of Dermatology, 98, 51.

Gibbs, K., and Walshe, J. M. (1966). Penicillamine and pyridoxine requirements in man. Lancet, 1, 175.

Golding, D. N. (1973). D-Penicillamine in rheumatoid arthritis. British fournal of Hospital Medicine, 9, 805.

Harris, E. D., and Sjoerdsma, A. (1966). Effect of penicillamine on human collagen and its possible application to treatment of scleroderma. Lancet, 2, 996.

Herbert, C. M., Lindberg, K. A., Jayson, M. I. V., and Bailey, A. J. (1974). Biosynthesis and maturation of skin collagen in scleroderma, and effect of D-penicillamine. Lancet, 1, 187.

Jaffe, I. A. (1963). Comparison of the effect of plasmapheresis and penicillamine on the level of circulating rheumatoid factor. Annals of the Rheumatic Diseases, 22, 71.

Moynahan, E. J. (1973). Morphoea (localized cutaneous scleroderma) treated with low-dosage penicillamine (4 cases, including Coup de Sabre). Proceedings of the Royal Society of Medicine, 66, 1083.

Oram, S., and Stokes, W. (1961). The heart in scleroderma. British Heart fournal, 23, 243.

Sackner, M. A., Akgun, N., Kimbel, P., and Lewis, D. H. (1964). The pathophysiology of scleroderma involving the heart and respiratory system. Annals of Internal Medicine, $60,611$.

Thomson, J., and Milne, J. A. (1974). Two years of penicillamine for progressive systemic sclerosis: a case report. Postgraduate Medical fournal, 50, August Suppl., 36.

Tio, H., van Wijk, J., and de Haan, E. (1973). Treatment of progressive systemic sclerosis (PSS) with penicillamine. Preliminary report of two cases. Acta Medica Scandinavica, 193, 477.

Walshe, J. M. (1956). Wilson's disease: new oral therapy. Lancet, 1, 25.

Walshe, J. M. (1960). Treatment of Wilson's disease with penicillamine. Lancet, 1, 188.

Requests for reprints to Dr. M. F. Muers, Chest Department, Churchill Hospital, Headington, Oxford OX3 $7 \mathrm{LJ}$. 